\title{
Prenatal environmental conditions underlie alternative reproductive tactics that drive the formation of a mixed-kin cooperative society
}

\author{
Shailee S. Shah ${ }^{1 *}$ and Dustin R. Rubenstein ${ }^{1,2}$ \\ ${ }^{1}$ Department of Ecology, Evolution, and Environmental Biology, Columbia University, 1200 Amsterdam \\ Avenue, New York, NY 10027 USA \\ ${ }^{2}$ Center for Integrative Animal Behavior, Columbia University, New York, NY 10027 USA \\ *Correspondence to: Shailee S. Shah \\ Email: $\underline{\text { shailee.shah@columbia.edu }}$
}

Author contributions: Both authors designed the study, collected and analyzed the data, and wrote the paper.

Competing Interest Statement: The authors declare no competing interests.

Keywords: alternative reproductive tactics; dispersal; inclusive fitness; cooperative breeding; mixed-kin society; direct benefits

This PDF file includes:

Abstract

Main Text

Figures 1 to 4

Tables 1 to 3 


\section{Abstract}

2 Although animal societies often evolve due to limited natal dispersal that results in kin clustering and

3 facilitates cooperation among relatives, many species form cooperative groups with low and variable kin

4 structure. Groups in such mixed-kin societies often comprise residents and immigrants of the same sex

5 that compete for breeding opportunities. To understand how such mixed-kin societies form despite their

6 potential for social conflict, we investigated the environmental causes and subsequent fitness

7 consequences of dispersal decisions in male cooperatively breeding superb starlings (Lamprotornis

8 superbus) that live in a climatically unpredictable environment. We show that the two alternative

9 reproductive tactics - natal dispersal or philopatry — exhibit reproductive tradeoffs resulting in equal

10 lifetime inclusive fitness. The tactic an individual adopts is governed by the environment its parents

11 experience prior to laying rather than the environment it experiences during its juvenile stage. When

12 individuals adopt the tactic not predicted by early life environmental conditions, their fitness is reduced.

13 Ultimately, climate-driven oscillating selection may help stabilize mixed-kin animal societies, despite

14 their reduced kin structure and potential for social conflict.

Main

17 Dispersal decisions that enable individuals to escape unfavorable environmental conditions or reduce

18 inbreeding risk also influence ecological and evolutionary processes like range expansion, gene flow, and

19 the formation of animal societies ${ }^{1,2}$. Limited natal dispersal - the permanent movement of an individual

20 from its natal to breeding site - plays a crucial role in social evolution by creating spatial clustering of kin

21 that facilitates cooperative care of young by relatives ${ }^{3-5}$. Although most animal societies are therefore

22 characterized by groups with high kin structure, a surprising number of species form social groups with

23 low kin structure ${ }^{6}$ that consist of same-sex residents and immigrants, which often compete for breeding

24 opportunities ${ }^{7-10}$. Since indirect benefits alone cannot explain the evolution of these mixed-kin societies

$25^{11-13}$, direct reproductive or survival benefits may underlie their formation ${ }^{7,9,14}$. Understanding how

26 mixed-kin cooperative societies form and remain stable despite their reduced kin structure and potential 
27 for high social conflict will require examining the causes and lifetime fitness consequences of individual

28 dispersal decisions to determine why some individuals remain in their natal groups with kin while others

29 do not.

31 Dispersal decisions are influenced not only by aspects of the social or ecological environment that

32 individuals experience during their lifetime after reaching nutritional independence ${ }^{15-17}$, but also by how

33 these factors affect their parents prior to birth and impact their development early-in-life (termed prenatal

34 factors) ${ }^{18,19}$. The influence of prenatal factors typically manifests via parental effects, modifications

35 provided by the mother or father to the offspring during development that alter offspring phenotype ${ }^{20}$.

36 Parental effects may be particularly important in cooperatively breeding species ${ }^{21}$, where parents can

37 limit offspring dispersal by influencing helping behavior or promote dispersal to reduce kin competition

$3819,22,23$. Although dispersal in most social species tends to be sex-biased ${ }^{24}$, in many cooperative breeders,

39 individuals of one sex can adopt either of two alternative reproductive tactics: natal dispersal or

40 philopatry ${ }^{8,15}$. Such sex-specific behavioral polyphenisms can exist either because (i) individuals face

41 conditional constraints in adopting the tactic with higher fitness and must instead make "the-best-of-a-

42 bad-job" by choosing the tactic with lower fitness ${ }^{25,26}$, or (ii) the relative fitness payoffs are

43 environmentally-dependent such that both tactics can persist within a population when conditions

44 fluctuate ${ }^{27,28}$. Consistent with the "best-of-a-bad-job" hypothesis, the fitness benefits of alternative

45 reproductive tactics in cooperative breeders tend to be unequal in the short-term ${ }^{29-32}$. Yet, few studies

46 have compared the lifetime inclusive fitness outcomes of alternative reproductive tactics, especially in

47 mixed-kin societies where they are most common ${ }^{8}$. Thus, the evolutionary mechanism underlying the

48 formation of mixed-kin societies remains largely unknown and can only be revealed by considering the

49 lifetime inclusive fitness consequences of alternative reproductive tactics.

51 Here, we leveraged a 16-year longitudinal dataset from Kenya to examine how reproductive tactics in

52 male cooperatively breeding superb starlings (Lamprotornis superbus) are influenced by ecological and 
53 social factors in both the prenatal and juvenile periods, and ultimately how these alternative tactics impact

54 lifetime inclusive fitness. Superb starlings are plural cooperative breeders in which both sexes help ${ }^{33,34}$,

55 and although males tend to be more philopatric than females, these mixed-kin social groups have low but

56 variable kin structure overall as well as within both sexes ${ }^{33,35}$. While resident females never breed in their

57 natal groups, both resident and immigrant males can acquire breeding status ${ }^{33}$. These savanna-dwelling

58 birds inhabit one of the most variable and unpredictable environments on earth ${ }^{36}$, where annual

59 fluctuation in seasonal rainfall governs insect prey availability ${ }^{37}$. Rainfall is most variable during the dry

60 season ${ }^{38}$, and this variation has been shown to influence many aspects of superb starling social behavior

61 and life-history. In particular, rainfall experienced by the parents (prenatal rainfall) influences offspring

62 sex ratio ${ }^{34}$, epigenetic modification of genes related to the avian stress response ${ }^{39}$, and male reproductive

63 decisions ${ }^{39}$. Dry season rainfall experienced by individuals of both sexes also influences access to

64 breeding opportunities ${ }^{40}$ and helping behavior ${ }^{41}$. In addition, the social environment (group size) also

65 impacts superb starling fitness, both survival ${ }^{42}$ and reproductive success ${ }^{38}$.

67 To examine the environmental causes of alternative reproductive tactics in superb starlings, we first

68 investigated how ecological and social factors during both the prenatal and juvenile stage influence male

69 dispersal decisions. We predicted that under harsh prenatal environmental conditions (low rainfall),

70 particularly for small groups with female-skewed sex ratios, parental effects may indirectly limit dispersal

71 of male offspring by promoting helping behavior. Additionally, males that remain in their natal group

72 would be more likely to provide alloparental care in their first year of life than males that ultimately

73 disperse. Similarly, male superb starlings that experience harsh environmental conditions as juveniles, the

74 life history stage when dispersal decisions are likely made ${ }^{33}$, would be more likely to remain in their natal

75 group in order avoid the costs of dispersal or reap the benefits of philopatry. Furthermore, a social

76 environment conducive to higher survival (i.e., when in larger groups) and with greater access to

77 reproductive opportunities (groups with female-skewed sex ratios) may also promote philopatry. Next, to

78 understand the fitness consequences of these alternative reproductive tactics, we compared access to 
79 reproductive opportunities, reproductive success, lifetime inclusive fitness, and survivorship of resident

80 and immigrant males. According to the best-of-a-bad-job hypothesis, we predicted that the two alternative

81 tactics would result in unequal lifetime inclusive fitness. Alternatively, if both dispersal and philopatry

82 maximize individual fitness, then the two tactics would have equal lifetime inclusive fitness but exhibit

83 reproductive tradeoffs such that individuals would have lower lifetime fitness when they adopt the

84 reproductive tactic not predicted by the prevailing environmental conditions. Ultimately, by linking the

85 environmental causes and fitness consequences of alternative reproductive tactics in a cooperative breeder

86 we will be able to determine how two fundamentally different reproductive phenotypes can persist and

87 potentially give rise to mixed-kin, plural breeding societies.

\section{Results}

90 Patterns of male dispersal

91 Consistent with previous reports in this species ${ }^{33}$, we found that males were the primary philopatric sex;

92 only 59 of 198 males (30\%) in our marked social groups for whom we had data on dispersal status (i.e.,

93 excluding individuals already present in the groups at the beginning of 2001 (dispersal status unknown)

94 and individuals not seen past one year of age (presumed dispersed)) were immigrants (compared to 121 of

$95248(49 \%)$ of females). However, among all males for whom we had complete life history data $(\mathrm{N}=162)$,

96 more than half the breeders $(30$ of $59 ; 51 \%)$ were immigrants.

98 Ecological and social predictors of male dispersal

99 Next, we examined the role of ecological and social factors experienced by males during their juvenile

100 stage (i.e., the period when dispersal occurs) as well as by their parents (i.e., prenatal) in influencing male

101 dispersal decisions. We found that harsh prenatal ecological conditions were associated with limited

102 dispersal such that males were less likely to disperse when they were born in years following low prenatal

103 rainfall $(Z=2.03, P=0.04, C I=0.02-0.74 ;$ Fig. 1, Table 1). Since prenatal ecological conditions did not

104 affect hatchling mass prior to fledging (see $S I$ ), this pattern was likely driven by dispersal, and not 
mortality. In contrast, the social environment as well as the ecological conditions experienced during the

106 juvenile period had no significant impact on the likelihood of males dispersing (Table 1). Together, these

107 results suggest that male dispersal is influenced more by (i) conditions experienced by their parents than

108 the conditions they experience as juveniles and (ii) ecological rather than social factors. Finally, we also

109 found that males that subsequently dispersed were less likely to act as alloparents in their first year of life

110 than males that subsequently remained in their natal group $\left(\chi^{2}{ }_{1}=7.63, \mathrm{P}=0.006\right)$.

\section{Fitness consequences of male dispersal decisions}

113 We then explored the fitness consequences of the different male dispersal decisions. More than half the

114 males in the population ( 85 of 152 males; 56\%) failed to accrue any inclusive fitness in their lifetimes

115 (Fig. S3) ${ }^{33}$. Residents unsurprisingly accrued higher indirect fitness than immigrants (Fig. 2C, U = 2103,

$116 \mathrm{P}=0.02$ ), who were unlikely to accrue meaningful indirect fitness in their natal group prior to dispersal

117 (see $S I$ ). In contrast, resident and immigrant males had similar direct and inclusive lifetime fitness (Fig.

118 2A-B; inclusive: $\mathrm{U}=2337, \mathrm{P}=0.22$; direct: $\mathrm{U}=2701, \mathrm{P}=0.59$ ). While this analysis does not quantify

119 indirect fitness accrued by immigrants in their natal group prior to dispersing, natal males that dispersed

120 accrued significantly lower fitness in their first year than residents, suggesting that immigrants into our

121 study population also did not likely accrue considerable fitness prior to dispersing (see $S I$ ). Nonetheless,

122 to account for the possibility that immigrant males accrued at least some indirect fitness in their natal

123 group prior to dispersal, we repeated our analysis after excluding fitness accrued by residents in their first

124 year of life. We found qualitatively similar results, with residents and immigrants still having similar

125 direct and inclusive fitness, as well as similar indirect fitness (see $S I$ ).

127 Although the survival likelihood of immigrants after successful dispersal is not significantly different

128 from that of residents $(Z=0.06, P=0.95, C I=-0.36-0.38)$ (Fig. $S 4)$, our analysis did not account for any

129 potential mortality of immigrants during dispersal. While we expect the mortality of immigrants to be low

130 because there are no floaters in this system ${ }^{33}$, to account for potential immigrant mortality during 
131 dispersal, we ran a sensitivity analysis that added immigrants with zero fitness in $10 \%$ increments to the

132 analyses of direct, indirect, and inclusive lifetime fitness. Our sensitivity analysis found that the mortality

133 threshold for immigrants at which direct fitness would be higher in residents than immigrants was $70 \%$

134 (Table S1). Similarly, the mortality threshold for immigrants at which inclusive fitness would be higher in

135 residents than immigrants ranged from $20 \%$ to $50 \%$, depending on whether first-year resident males were

136 included in the analysis (Table S1). Together, these results indicate that resident and immigrant males

137 have similar lifetime inclusive fitness, even when accounting for the potential of mortality during

138 dispersal.

140 Despite similar lifetime inclusive fitness, immigrants were more likely than residents to breed at least 141 once in their lifetimes $\left(\chi_{1}^{2}=7.39, \mathrm{P}=0.006\right)$, had higher lifetime breeding effort (the number of breeding 142 attempts as a proportion of an individual's adult lifespan) $(\mathrm{U}=3869, \mathrm{P}=0.006)$, and began breeding at a

143 younger age $(\mathrm{U}=265.5, \mathrm{P}=0.01)$. In contrast, residents that did breed had higher nest success than

144 immigrant breeders $(\mathrm{Z}=2.46, \mathrm{P}=0.01, \mathrm{CI}=0.27-2.34)$. In addition, both lifetime breeding effort and

145 dispersal status affected a male's likelihood of accruing some nonzero inclusive fitness during his lifetime

146 (Fig. 3A, Table 2). Among males with some lifetime inclusive fitness, residents accrued higher inclusive

147 fitness than immigrants with the same amount of lifetime breeding effort (Fig. 3B, Table 2).

149 Finally, we assessed whether there were reproductive tradeoffs for individuals that adopted the tactic not

150 predicted by prenatal ecological conditions. Since we did not have precise rainfall data from the

151 immigrants' natal sites (though rainfall is highly spatially correlated and temporally synchronous within

152 the dispersal radius of our study site; see $S I$ ), we used a categorical measure of prenatal rainfall based on

153 the mean long-term pre-breeding rainfall at our study site (see Methods and $S I$ ). Consistent with the idea

154 of reproductive tradeoffs and the hypothesis that the fitness consequences of alternative reproductive

155 tactics depend on prenatal environmental conditions, we found that immigrant males were more likely to

156 accrue nonzero lifetime inclusive fitness when born following periods of high prenatal rainfall, but that 
157 residents were more likely to accrue nonzero lifetime inclusive fitness when born following periods of

158 low prenatal rainfall (Fig. 4, Table 3).

160 Discussion

161 Although mixed-kin cooperative groups characterized by low relatedness are surprisingly common (45\%

162 of all cooperatively breeding birds) ${ }^{6}$, it remains unclear how these societies arise and are maintained given

163 the potential for high social conflict among unrelated group members competing for reproductive

164 opportunities. We examined the environmental causes and inclusive fitness consequences of dispersal

165 decisions in male superb starlings living in a climatically variable and unpredictable savanna environment

$166^{36,42}$, for whom philopatry and dispersal can both be pathways to reproductive opportunities ${ }^{33}$. We found

167 that dispersal in males is influenced by their parents' prenatal environment rather than the environment

168 that the males experience as juveniles, suggesting that prenatal parental effects play an important role in

169 governing dispersal decisions. Ultimately, natal dispersal and philopatry had equal lifetime inclusive

170 fitness outcomes, meaning that they are two equal, alternative male reproductive tactics. Yet, the two

171 tactics showed reproductive tradeoffs - immigrants had greater access to reproductive opportunities via

172 the acquisition of dominant breeding positions, whereas residents that bred had higher reproductive

173 success. When males adopted a tactic not predicted by prevailing prenatal environmental conditions, their

174 lifetime inclusive fitness was reduced. Together, these results suggest that environmental variability

175 experienced early in life may help maintain a reproductive polyphenism with equal lifetime inclusive

176 fitness, which ultimately enables the formation and persistence of a mixed-kin cooperative society in an

177 unpredictable environment.

179 Unlike in other cooperatively breeding species where conditions experienced during the juvenile stage

180 shape dispersal decisions ${ }^{15,16,43}$, male dispersal in superb starlings was only governed by prenatal

181 ecological conditions. Although we were unable to directly distinguish between dispersal and morality,

182 several lines of evidence — including the modal age at which natal males disappear from and modal age of 
183 immigrants into our study population, the age at which males reach sexual maturity, the close match in

184 the proportions of dispersers and immigrants, the increased likelihood of dispersal following benign

185 ecological conditions, no effect of prenatal ecological conditions on hatchling mass prior to fledging, and

186 the high likelihood of post-fledgling survival from year-to-year ${ }^{42}$ - strongly suggest that the pattern we

187 observed is driven by dispersal, and not mortality (see Methods and SI for further details). The effect of

188 prenatal conditions on dispersal suggests that parental effects influence the dispersal phenotype of male

189 superb starlings, a result that has been suggested previously for male reproductive opportunities in this

190 species ${ }^{39}$. Parental effects, which can result from physiological or molecular modifications to offspring

191 during development ${ }^{20}$, may be particularly important in cooperatively breeding species ${ }^{21}$ and species

192 inhabiting unpredictable environments ${ }^{44}$. While the specific physiological mechanisms of prenatal

193 parental effects on dispersal remain unknown for this species, previous studies have demonstrated an

194 effect of maternal condition on offspring sex allocation, maternal investment in eggs, and DNA

195 methylation in superb starlings ${ }^{34,39}$ and other vertebrates ${ }^{23,45,46}$. Studies of two other avian species,

196 western bluebirds (Sialia mexicana) and great tits (Parus major), found an effect of maternal androgen

197 deposition on offspring dispersal in response to ecological conditions ${ }^{18,19}$. Viviparous lizards (Lacerta

198 vivipara) show a similar effect ${ }^{46}$, and maternal hormones have also been shown to increase helping

199 behavior in subordinate female meerkats (Suricata suricatta) ${ }^{22}$. Alternatively, conditions experienced by

200 parents may affect their behavior towards their offspring after birth, such that dispersal is driven purely by

201 behavioral interactions prior to offspring becoming self-sufficient ${ }^{47,48}$. Further work in this and other

202 cooperatively breeding species should examine the mechanism by which environmentally-mediated

203 parental effects might influence future reproductive tactics adopted by offspring.

205 Parental effects can be selfish, to manipulate offspring phenotype in order to increase parental fitness, or 206 anticipatory, to maximize offspring fitness ${ }^{21,49}$. We know that offspring sex ratio in superb starlings is

207 male-biased when mothers are in poorer body condition following harsher prenatal conditions, a pattern

208 that suggests that females maximize their inclusive fitness in an unpredictable environment by investing 
209 in the sex with lower fitness variance ${ }^{34}$. However, our results suggest that mothers could also be

210 influencing cooperative behavior in their offspring because males that participated in alloparental care in

211 their first year of life were subsequently more likely to remain in their natal group. Male superb starlings

212 are more likely to become alloparents and help more than females ${ }^{38}$, and alloparents buffer the

213 detrimental effects of harsh environmental conditions on reproductive success in this species ${ }^{41}$. Thus,

214 prenatal parental effects promoting alloparental behavior following harsher prenatal conditions might

215 serve to selfishly increase the parents' short-term future reproductive success and indirectly limit

216 dispersal of male offspring ${ }^{22}$. Although males born following benign prenatal conditions could,

217 conversely, be more likely to disperse so as to reduce kin competition, this seems less probable because

218 kin competition has actually been shown to decrease under benign environmental conditions in other

219 cooperatively breeding species ${ }^{50,51}$. Additionally, our results are consistent with the hypothesis that

220 prenatal parental effects on dispersal in males are anticipatory because when males adopted the tactic

221 predicted by the prevailing prenatal ecological conditions, they were more likely to accrue some inclusive

222 fitness in their lifetimes. Since more than half of superb starling males fail to accrue any fitness in their

223 lifetimes, largely due to high nest predation pressure ${ }^{33}$, securing any amount of nonzero lifetime fitness is

224 crucial in this species, an idea consistent with the bet-hedging hypothesis proposed for this ${ }^{38}$ and other

225 social species ${ }^{52}$. Males born following harsh prenatal conditions thus appear to benefit from avoiding the

226 costs of dispersal and remaining in their natal group ${ }^{17,53}$, whereas males born following benign conditions

227 might be better able to cope with the costs of dispersal and maximize their fitness by immigrating into

228 another social group ${ }^{31}$.

230 In contrast to other studies in kin-only cooperatively breeding societies ${ }^{29,30,54-57}$, we found that the two

231 reproductive tactics adopted by males — natal dispersal and philopatry — have equal lifetime inclusive

232 fitness in a mixed-kin cooperative society. Although resident males had significantly higher lifetime

233 indirect reproductive success than immigrants, an unsurprising result given the kin structuring among

234 males in superb starling social groups ${ }^{33}$, this was more than balanced out by the relatively larger 
235 contribution of lifetime direct fitness, even when accounting for potential mortality during dispersal.

236 While it was not logistically possible to compare the fitness of resident and dispersing males born to the

237 same social group, our approach of comparing resident to immigrant males has proven informative in

238 other avian studies ${ }^{58}$. While we do not have an estimate of dispersal mortality in this species, we have

239 never observed floaters in our study area, suggesting that individuals move from their natal group to their

240 non-natal group over a relatively short time period and likely do not incur significant mortality in transit

$241{ }^{33}$. Following successful dispersal, our results show that the survival likelihood of immigrants is similar to

242 that of resident males. Furthermore, natal males that subsequently remain in their natal group accrue

243 significantly higher indirect fitness in their first year of life, suggesting that immigrants are unlikely to

244 accrue considerable indirect fitness in their natal group prior to dispersing. Yet, when even accounting for

245 this possibility, immigrant and resident males still had similar lifetime inclusive fitness. Similar variation

246 in alloparental effort and indirect fitness in relation to dispersal tactics has been shown in other

247 cooperatively breeding species ${ }^{58,59}$.

249 Finally, we also show that the equal lifetime inclusive fitness outcomes of the two dispersal tactics are

250 due to a reproductive tradeoff, an idea that has been proposed theoretically ${ }^{28,60}$ but rarely tested

251 empirically. Although immigrant superb starlings had greater access to reproductive opportunities via the

252 acquisition of dominant breeding positions with the group, residents that acquired breeding positions were

253 more likely to successfully fledge young. Residents can therefore afford to have lower access to breeding

254 opportunities over their lifetimes since they have higher nest success. This higher nest success is likely

255 due to greater alloparental care at nests of resident males who have more kin in the group to act as helpers

256 than do immigrants ${ }^{61-63}$. Thus, for superb starling males, philopatry leads to lower reproductive quantity

257 but higher quality, whereas dispersal results in higher reproductive quantity but lower quality. Since

258 immigrants and residents are equally likely to survive from one breeding season to the next, these

259 differences in reproductive quality and quantity are unrelated to longevity ${ }^{29}$. Together these results

260 suggest that the two alternative dispersal tactics are equivalent in terms of lifetime inclusive fitness and 
261 refute the hypothesis that remaining in the natal group — the tactic favored following harsh prenatal

262 conditions - is simply making "the-best-of-a-bad-job" 25,26 . The coexistence of resident and immigrant

263 males in cooperative social groups has been shown to be similarly facilitated by equal reproductive rates

264 in spotted hyenas (Crocuta crocuta $)^{8}$ and inclusive fitness at different age stages in dwarf mongooses

265 (Helogale parvula) ${ }^{64}$, both species that live in mixed-kin societies. However, to the best of our

266 knowledge, ours is the first study in a cooperatively breeding vertebrate to demonstrate equal lifetime

267 inclusive fitness outcomes of alternative dispersal tactics.

269 This behavioral polyphenism in reproductive tactics is likely maintained by a flexible response to high

270 and unpredictable environmental variability ${ }^{27}$. A temporally variable and unpredictable environment has

271 been shown both theoretically ${ }^{28}$ and empirically ${ }^{65}$ to generate conditional strategies that result in a

272 developmental switch between alternative tactics. If alternative reproductive tactics have a strong genetic

273 (or perhaps epigenetic) basis ${ }^{66,67}$, environmental variability can reverse the selective differential between

274 the two tactics from one year to the next, resulting in alternative tactics with equal fitness outcomes ${ }^{28,68}$.

275 The savanna habitat inhabited by superb starlings has high temporal ecological variability ${ }^{36,38}$ that may

276 allow both dispersal tactics to persist, resulting in the formation of mixed-kin cooperative groups.

277 Interestingly, spotted hyenas ${ }^{69}$ and dwarf mongooses ${ }^{64}$ experience the same unpredictable African

278 savanna environments as superb starlings, suggesting that environmental uncertainty—and perhaps

279 oscillating selection pressures more generally—maintains alternative dispersal tactics and leads to the

280 formation of and/or stabilizes societies with low kin structure. Oscillating selection may be particularly

281 important in arid and semi-arid environments where climatic variability is high ${ }^{68}$, and may help explain

282 the evolution of both mixed-kin societies and plural breeding more generally. Indeed, many other plural

283 cooperatively breeding birds across the globe live in harsh arid and semi-arid environments characterized

284 by unpredictable variation in rainfall and food resources ${ }^{13,70-77}$. While we do not yet know whether

285 dispersal has a genetic basis in superb starlings - though there are indications of a potential epigenetic

286 basis ${ }^{39}$ - our results suggest that the two tactics face oscillating selection since the relative lifetime 
287 inclusive fitness of the two tactics fluctuates in response to prenatal environmental conditions. Ultimately,

288 identifying the mechanism by which prenatal parental effects lead to developmental differences that

289 determine male reproductive tactics will be important for understanding the role that environmentally-

290 driven selection pressures play in shaping behavioral polyphenisms in this and other social species.

292 In summary, we have shown that natal dispersal and philopatry in male cooperatively breeding superb

293 starlings represent two alternative reproductive tactics with equal lifetime inclusive fitness. The tactics are

294 likely mediated by parental effects during development and are maintained by oscillating selection

295 pressures characteristic of their variable and unpredictable savanna environment. Our study suggests a

296 direct link between environmental uncertainty, behavioral polyphenism, and the evolution of mixed-kin

297 animal societies that cannot be explained by indirect fitness benefits alone. Our work also underscores the

298 importance of prenatal environmental conditions and parental effects in determining offspring phenotype,

299 especially in cooperative societies where early life conditions have direct implications on the future

300 fitness of both parents and offspring. Moreover, the direct benefits derived from environmental selective

301 pressures appear to play a significant role in the evolution and maintenance of cooperative societies,

302 alongside or in the absence of kin selection. Ultimately, understanding how fluctuation in early life

303 environmental conditions helps mediate reproductive tradeoffs and lifetime fitness is critical in an era of

304 rapid anthropogenic climate change because climatic uncertainty is only likely to increase across much of

305 the globe for the foreseeable future.

\section{Materials and Methods}

\section{Data collection}

309 Nine superb starling social groups have been monitored continuously since 2001 at the Mpala Research

310 Centre, Kenya $\left(0^{\circ} 17^{\prime} \mathrm{N} 37^{\circ} 52^{\prime} \mathrm{E}\right)^{33,78}$. The study population is distributed over a $9 \mathrm{~km}$ extent from North

311 to South. Groups (mean size $\pm \mathrm{SD}=22 \pm 12$ ) defend stable territories year-round and consist of breeding

312 (mean $\pm \mathrm{SD}=2.70 \pm 1.49$ pairs per group) and non-breeding individuals, some of whom act as 
313 alloparents that guard and/or provision young ${ }^{33,41}$. Birds breed twice a year during the long (March-June)

314 and short rains (October-November) ${ }^{33}$. We used data from the beginning of the 2001 short rains breeding

315 season through the end of the 2017 long rains breeding season $(\mathrm{N}=33$ breeding seasons over 16 years),

316 since not all birds in the study population were banded in the first breeding season. Limited focal

317 observation data for nests in 2001 short rains was accounted for in our analyses (see Data Analysis).

319 Birds were banded with a unique combination of colored leg bands and a numbered metal ring.

320 Hatchlings were banded in the nest; all other individuals were captured in baited pull-string traps or mist

321 nets and banded after fledging from the nest ${ }^{78}$. If banded post-fledgling, age was assessed via eye color as

322 fledgling (black eyes), sub-adult (less than one year of age; cloudy eyes), or adult (one year of age or

323 older; white eyes) ${ }^{42}$. Dispersal status (i.e., resident or immigrant) was assigned based on age at banding

324 and genetic parentage. Residents were either banded as hatchlings in the nest or as juveniles whose

325 parents were genetically identified as members of the same group using 15 microsatellite markers ${ }^{79}$.

326 Immigrants were defined as those banded as juveniles or older whose parents were not genetically

327 identified as belonging to the same group. We also used the same microsatellite markers to estimate (i)

328 parentage and direct reproductive success in Cervus v3.0 ${ }^{80}$ using methods described previously for this

329 species ${ }^{40,81-83}$ and (ii) pairwise relatedness ${ }^{84}$ between all individuals with the R package related ${ }^{85}$. Sex

330 was determined genetically ${ }^{86}$ as previously described for this species ${ }^{78}$.

332 We performed daily nest searches throughout the breeding season. Active nests were observed with a 333 spotting scope for 60-120 min per observation period (total observation time per nest: mean $\pm \mathrm{SD}=$

$334314.33 \pm 248.82 \mathrm{~min}$ ). All superb starlings within $30 \mathrm{~m}$ of the nest were identified, and their times of

335 arrival and departure were recorded ${ }^{83}$. Parents are the primary nest builders, and only the mother

336 incubates the eggs ${ }^{83}$. All other members of the social group seen visiting or guarding the nest were

337 categorized as alloparents ${ }^{41}$. 
339 Census data were used to estimate group size and sex ratio (calculated by dividing the number of males

340 by the sum of number of males and immigrant females in the group to estimate potential mate

341 competition. Natal females were excluded since they never breed and are thus not viable mates for males

342 in the group). Groups were opportunistically censused year-round and each individual marked as either

343 present or absent in its social group twice a year in six-month increments. Individuals not seen for five or

344 more breeding seasons (i.e. 2.5 years) were assumed to be dead ${ }^{35,42}$. We inferred that the dispersal

345 window for males is between fledging and around one year of age (age of sexual maturity) using four

346 lines of evidence: (i) the modal age at which males disappear from their natal group; (ii) the categorical

347 age of immigrant males dispersing into the study population; (iii) the likelihood of males being detected

348 in the census in their first year of life; and (iv) the minimum age of first breeding by resident males (see

$349 S I$ for details). If a male was observed in its natal group after one year of age, we classified it as a

350 resident; if not, we classified it as having dispersed. Although we could not distinguish between dispersal

351 and mortality, the positive relationship between the likelihood of dispersal and benign ecological

352 conditions (see Results) suggests that these males did indeed disperse since we would have expected a

353 negative relationship if mortality were higher following harsh ecological conditions. In addition, we

354 found no variation in hatchling mass before fledging (measured at 10 days of age) with variation in

355 ecological conditions, further suggesting that this pattern is driven by dispersal not mortality (see $S I$ ).

356 Following the same lines of evidence, immigrant males were assumed to have entered the group at about

357 one year of age (see $S I)$.

359 We considered the period between end of the breeding season when a male is born to the beginning of the

360 breeding season one year later (i.e., its juvenile stage) as its dispersal window (see SI for more details).

361 Ecological and social conditions experienced by juveniles in this period were termed juvenile stage

362 conditions. In contrast, ecological and social conditions experienced by parents in the pre-breeding period

363 preceding the breeding season of an individual's birth were termed prenatal conditions. A breeding season

364 was defined as the period between two weeks before the first nest and two weeks after the last nest of the 
season. The period between breeding seasons was termed the pre-breeding period. Daily rainfall was measured using an automated Hydrological Services TB3 Tipping Bucket Rain Gauge at Mpala Research

367 Centre ${ }^{87}$, supplemented by a manual gauge at the same location when the automated gauge failed ${ }^{38}$. To

368 calculate prenatal and juvenile period rainfall, we summed the rainfall within the prenatal and juvenile

369 stages of an individual's lifetime, as defined above.

\section{$371 \quad$ Data analysis}

372 Our dataset comprises individuals that are (i) known to have been born in the groups ("natal"), (ii) known

373 to have immigrated into the group (“immigrant”), and (iii) were already part of the group in 2001 when

374 the study population was banded. All individuals are either known to have disappeared (classified as

375 either "dead" or "dispersed" depending on age at disappearance) or were still present in the study

376 population in 2017. Natal individuals that did not disperse were termed "residents". Thus, individuals

377 with "known complete life histories" are natal and immigrant individuals who were classified as dead.

379 Using data from individuals with known complete life histories as well as natal individuals that are still

380 alive and present in the study population past one year of age $\left(\mathrm{N}_{\mathrm{M}}=198, \mathrm{~N}_{\mathrm{F}}=248\right)$, we first examined

381 patterns of male dispersal by quantifying the proportion of immigrant adult males and females in the

382 study population. We then determined how breeding opportunities were shared between immigrants and

383 residents by calculating the proportion of immigrant breeders of both sexes in the study population using

384 data from breeders with known complete life histories $\left(\mathrm{N}_{\mathrm{M}}=59, \mathrm{~N}_{\mathrm{F}}=121\right)$.

386 Next, using data from all natal males — including those classified as dispersed or dead as well as those still

387 present in the study population past the age of 1 year in 2017-we investigated the effect of ecological

388 and social conditions during the prenatal and juvenile stages on the likelihood of a male dispersing. We

389 built a generalized linear mixed model (GLMM) with a binomial error structure and "logit" link function.

390 We used the binomial response of reproductive tactic $(1=$ dispersed, $0=$ remained $)$ as the dependent 
391 variable $\left(\mathrm{N}_{\text {dispersed }}=52, \mathrm{~N}_{\text {remained }}=133\right)$. Fixed effects, which were standardized using z-scores ${ }^{88}$, included

392 prenatal and juvenile stage rainfall, prenatal group size, and prenatal sex ratio. Since group size and sex

393 ratio were highly correlated within a year (group size: Pearson's $r=0.95$; sex ratio: Pearson's $r=0.80$ ),

394 we only included prenatal group size and sex ratio in the final model. All two-way interactions were

395 included in the model, but later removed if their effect was not significant ${ }^{89}$. Breeding season of birth,

396 season (long vs. short rains), social group, mother ID, and father ID were included as random effects. All

397 random effects other than breeding season of birth had variance components equal to zero and were thus

398 removed from the final model to facilitate the computation of $95 \%$ confidence intervals. This had no

399 effect on the estimates of fixed effects ${ }^{90}$. Furthermore, to investigate the relationship between alloparental

400 care provided by males prior to reaching one year of age and their subsequent reproductive tactic, we used

401 a Chi-square test to compare alloparental status (ever alloparent/never alloparent) and reproductive tactic

402 (dispersed/remained) for all natal males $(\mathrm{N}=185)$.

404 Finally, we sought to understand the fitness consequences of the alternative reproductive tactics using 405 data from males with known complete life histories. Although it was not possible to compare the fitness 406 consequences of the alternative reproductive tactics adopted by males born from same social group (since 407 dispersers rarely remain within the study population; only 3 males in 16 years), we compared access to 408 reproductive opportunities, reproductive success, lifetime inclusive fitness, and survivorship of resident 409 and immigrant males. Previous studies of cooperatively breeding birds have used the same approach ${ }^{58}$. 410 Access to reproductive opportunities was quantified as: (i) the likelihood of a male ever breeding in its 411 lifetime (Chi-squared test) $\left(\mathrm{N}_{\mathrm{Imm}}=59, \mathrm{~N}_{\mathrm{Res}}=103\right)$; (ii) lifetime breeding effort, or the number of breeding 412 attempts as a proportion of an individual's adult lifespan (Mann-Whitney test with continuity correction) $413\left(\mathrm{~N}_{\text {Imm }}=59, \mathrm{~N}_{\text {Res }}=103\right)$; and (iii) for males that bred at least once $\left(\mathrm{N}_{\text {Imm }}=30, \mathrm{~N}_{\text {Res }}=29\right)$, the age at first

414 breeding (Mann-Whitney test with continuity correction). To evaluate the likelihood of a male obtaining 415 any reproductive success in their lifetimes, we modeled the effect of dispersal status on nest success $(1=$ 416 succeeded, 0 = failed) using a GLMM with a binomial error structure and "logit" link function $\left(\mathrm{N}_{\text {Succeeded }}\right.$ 
$417=49, \mathrm{~N}_{\text {Failed }}=229$ ). Since some males nested multiple times in their lifetimes, we included individual ID

418 as a random effect in the model along with social group and breeding season.

420 Following Green and Hatchwell ${ }^{58}$, we calculated lifetime inclusive fitness (I) as the sum of lifetime direct

421 and indirect fitness according to the equation

422

$$
I=\left[\sum_{j=1}^{J} M_{j} E R-\frac{\sum_{j=1}^{J} \Sigma_{n=1}^{N_{j}} \Sigma_{m=1}^{M_{j}} e_{n j} r_{m n j}}{2}\right]_{\text {direct fitness }}+\left[\sum_{o=1}^{O} \sum_{m=1}^{M_{o}} e_{o} r_{m o}\right]_{\text {indirect fitness }}
$$

425 where direct fitness was calculated as the product of the number of fledglings per nest $\left(\mathrm{M}_{\mathrm{j}}\right)$, paternal care

426 effort $(E=0.5$, the other half being attributed to the mother), and the mean offspring-father relatedness ( $R$

$427=0.5)$ summed over all successful nests $(\mathrm{J})$, minus half of the indirect fitness attributed to alloparents (the

428 other half being subtracted from the mother's direct fitness). Indirect fitness attributed to alloparents at

429 each nest was calculated as the product of the mean alloparental effort at a nest per social group per

430 breeding season $\left(\mathrm{e}_{\mathrm{nj}}\right)$ and the alloparent's relatedness to the fledglings $\left(\mathrm{r}_{\mathrm{mnj}}\right)$, summed over all fledglings

$431\left(\mathrm{M}_{\mathrm{j}}\right)$ and alloparents at the nest $\left(\mathrm{N}_{\mathrm{j}}\right)$ for all successful nests $(\mathrm{J})$. Alloparents with $\mathrm{r}_{\mathrm{mnj}} \leq 0$ received no

432 indirect fitness. Indirect fitness of the focal male was similarly calculated as the product of the mean

433 alloparental effort $\left(e_{o}\right)$ and its relatedness to the fledglings $\left(r_{m o}\right)$, summed over all of the nests he visited in

434 his lifetime $(\mathrm{O})$. We used population means instead of individual measures of alloparental effort because

435 total observation time for nests varied. Alloparental effort was calculated as the proportion of time an

436 individual spent attending a nest (both guarding and bringing food) relative to the length of the

437 observation period ${ }^{41}$.

439 We compared the lifetime inclusive, direct, and indirect fitness of resident and immigrant males using a

440 Mann-Whitney test with continuity correction $\left(\mathrm{N}_{\mathrm{Imm}}=53, \mathrm{~N}_{\mathrm{Res}}=99\right)$. Since males accrue indirect fitness

441 as juveniles, we excluded males born in 2001 short rains, the earliest breeding season in our dataset, 
442 during which limited focal observations were conducted at nests. To account for indirect fitness accrued

443 by immigrant males in their natal group prior to dispersing, we additionally (i) compared fitness of

444 residents and immigrants after excluding fitness accrued by residents during the first year of their life (see

445 SI), and (ii) compared the fitness accrued in the first year of life by natal males that remained in their natal

446 group to that accrued by natal males that subsequently dispersed (see $S I$ ). To account for mortality during

447 dispersal, we conducted a sensitivity analysis by adding incremental proportions of immigrants with zero

448 lifetime fitness to the dataset (see $S I$ ).

450 To determine whether differences in reproductive access and success between resident and immigrant

451 males affected their lifetime inclusive fitness, we used GLMMs to model the effect of lifetime breeding

452 effort and dispersal status on lifetime inclusive fitness of males. The first model had a binomial response

453 (zero/nonzero lifetime inclusive fitness) and a "logit" link function $\left(\mathrm{N}_{\mathrm{Imm}}=53, \mathrm{~N}_{\text {Res }}=99\right)$. The second

454 model had a continuous dependent variable of all nonzero inclusive fitness observations $\left(\mathrm{N}_{\mathrm{Imm}}=20, \mathrm{~N}_{\mathrm{Res}}\right.$

$455=47)$ with an "identity" link function and a gamma error distribution. The fixed effects for both models

456 were lifetime breeding effort and dispersal status. Social group was included as a random effect, but later

457 removed from the second model, where its variance component equaled zero, to facilitate the computation

458 of $95 \%$ confidence intervals ${ }^{90}$.

460 We also built a GLMM to investigate the lifetime fitness consequences of adopting the tactic not

461 predicted by the prevailing environmental conditions, with a binomial response variable (zero/nonzero

462 lifetime inclusive fitness) and prenatal rainfall and dispersal status as fixed effects $\left(\mathrm{N}_{\text {Imm }}=53, \mathrm{~N}_{\text {Res }}=99\right)$.

463 Although we did not have precise rainfall data from the immigrants' natal sites, we used monthly rainfall

464 data from three sites within the dispersal radius $(\sim 30 \mathrm{~km})$ (Shah and Rubenstein, unpubl. data) of our

465 study population (Mpala Research Centre, MRC)—UHURU Central (12 km from MRC) ${ }^{91}$, UHURU

466 North (20 km from MRC) ${ }^{91}$, and Nanyuki (38 km from MRC) (East African Livestock Early Warning

467 System) - to demonstrate high spatiotemporal correlation of prenatal rainfall for immigrant and resident 
468 males (Table S1). Nonetheless, to take a more conservative approach, we used a categorical measure

469 based on mean long-term pre-breeding rainfall at Mpala Research Centre (low prenatal rainfall: rainfall $\leq$

470 long-term mean; high prenatal rainfall: rainfall > long-term mean). Rainfall within $10 \mathrm{~mm}$ of the long-

471 term mean was categorized as "low" to account for the accuracy of the rainfall gauge ${ }^{87}$.

473 Finally, we used a time-varying Cox proportional hazard model to determine whether dispersal status

474 affected male survival $\left(\mathrm{N}_{\mathrm{Imm}}=59, \mathrm{~N}_{\mathrm{Res}}=103\right)^{42}$. The model was built using the $\mathrm{R}$ package survival $^{92}$.

475 We checked that our dataset did not violate the proportional hazard assumption using the "cox.zph"

476 function. Social group was included as a random factor. We performed all data analysis in $\mathrm{R}^{93}$. VIF $<2$

477 for all fixed effects in GLMMs, excluding interaction terms ${ }^{94}$.

479 Data Availability. Data and R code will be made available on Dryad.

481 Acknowledgements. We thank B. Heidinger, M. Uriarte, M. VanAcker, J. Jensen, P. Downing, S. Caro, 482 S. Siller, Y. Cheng, A. Earl, J. Guan, S. Guindre-Parker, Y. Haba, E. Greig, R. Gloag, M. Paquet, and an 483 anonymous reviewer for statistical advice and comments on the manuscript. We are grateful to W.

484 Watetu, G. Manyaas and J. Mosiany for their assistance in the field, as well as all other volunteers, 485 students and field assistants that have contributed to this project since its inception in 2001. 
487 1. Matthysen, E. Multicausality of dispersal : a review. in Dispersal Ecology and Evolution (Oxford $488 \quad$ University Press, 2012).

489 2. Taylor, P. D. Altruism in viscous populations - an inclusive fitness model. Evol. Ecol. 6, 352-356 $490 \quad$ (1992).

491 3. Emlen, S. T. Benefits, constrainsts and the evolution of the family. Trends Ecol. Evol. 9, 282-285 492 (1994).

493 4. Hamilton, W. D. The Genetical Evolution of Social Behavior II. J. Theor. Biol. 7, 1-52 (1964).

494 5. Hamilton, W. D. The genetical evolution of social behaviour. I. J. Theor. Biol. 7, 1-16 (1964).

495 6. Riehl, C. P. Evolutionary routes to non-kin cooperative breeding in birds. Proc. R. Soc. London B 496 Biol. Sci. 280, 20132245 (2013).

497 7. Baglione, V., Marcos, J. M., Canestrari, D. \& Ekman, J. Direct fitness benefits of group living in a 498 complex cooperative society of carrion crows, Corvus corone corone. Anim. Behav. 64, 887-893 499 (2002).

500 8. Davidian, E., Courtiol, A., Wachter, B., Hofer, H. \& Höner, O. P. Why do some males choose to 501 breed at home when most other males disperse? Sci. Adv. 2, e1501236 (2016).

502 9. Kaiser, S. A., Martin, T. E., Oteyza, J. C., Armstad, C. \& Fleischer, R. C. Direct fitness benefits 503 and kinship of social foraging groups in an Old World tropical babbler. Behav. Ecol. 29, 468-478 504 (2018).

505 10. Reyer, H. U. Flexible helper structure as an ecological adaptation in the pied kingfisher (Ceryle 506 rudis rudis L.). Behav. Ecol. Sociobiol. 6, 219-227 (1980).

507 11. Rubenstein, D. R. \& Abbot, P. The evolution of social evolution. in Comparative Social Evolution 508 (eds. Rubenstein, D. R. \& Abbot, P.) 1-18 (Cambridge University Press, 2017).

$509 \quad$ doi:10.1017/9781107338319.002.

510 12. Liu, M. et al. The genetic relatedness in groups of joint-nesting Taiwan yuhinas: Low genetic 511 relatedness with preferences for male kin. PLoS One 10, 1-15 (2015). 
512 13. Riehl, C. P. \& Jara, L. Natural history and reproductive biology of the communally breeding

513 Greater Ani (Crotophaga major) at Gatún Lake, Panama. Wilson J. Ornithol. 121, 679-687 (2009).

514 14. Clutton-Brock, T. H. Breeding together: kin selection and mutualism in cooperative vertebrates.

$515 \quad$ Science (80-. ). 296, 69-72 (2002).

516 15. Nelson-Flower, M. J., Wiley, E. M., Flower, T. P. \& Ridley, A. R. Individual dispersal delays in a 517 cooperative breeder: Ecological constraints, the benefits of philopatry and the social queue for 518 dominance. J. Anim. Ecol. (2018) doi:10.1111/1365-2656.12814.

519 16. Baglione, V., Canestrari, D., Marcos, J. M. \& Ekman, J. Experimentally increased food resources 520 in the natal territory promote offspring philopatry and helping in cooperatively breeding carrion crows. Proc. R. Soc. B Biol. Sci. 273, 1529-1535 (2006).

522 17. Eikenaar, C., Brouwer, L., Komdeur, J. \& Richardson, D. S. Sex biased natal dispersal is not a 523 fixed trait in a stable population of Seychelles warblers. Behaviour 147, 1577-1590 (2010).

524 18. Tschirren, B., Fitze, P. S. \& Richner, H. Maternal modulation of natal dispersal in a passerine bird: An adaptive strategy to cope with parasitism? Am. Nat. 169, 87-93 (2007).

19. Duckworth, R. A. Maternal effects and range expansion: A key factor in a dynamic process?

Philos. Trans. R. Soc. B Biol. Sci. 364, 1075-1086 (2009).

528 20. Mousseau, T. A. \& Fox, C. W. The adaptive significance of maternal effects. Trends Ecol. Evol. $529 \quad \mathbf{1 3}, 403-407(1998)$.

530 21. Russell, A. F. \& Lummaa, V. Maternal effects in cooperative breeders: From hymenopterans to 531 humans. Philos. Trans. R. Soc. B Biol. Sci. 364, 1143-1167 (2009).

532 22. Dantzer, B. et al. The development of individual differences in cooperative behaviour: Maternal 533 glucocorticoid hormones alter helping behaviour of offspring in wild meerkats. Philos. Trans. R. $534 \quad$ Soc. B Biol. Sci. 374, (2019).

535 23. Silk, J. B. \& Brown, G. R. Local resource competition and local resource enhancement shape 536 primate birth sex ratios. Proc. R. Soc. B Biol. Sci. 275, 1761-1765 (2008).

537 24. Greenwood, P. J. \& Harvey, P. H. The natal and breeding dispersal of birds. Annu. Rev. Ecol. Syst. 
539 25. Koprowski, J. L. Alternative reproductive tactics in male eastern gray squirrels: 'making the best $540 \quad$ of a bad job'. Behav. Ecol. 4, 165-171 (1993).

541 26. Dawkins, R. Good strategy or evolutionarily stable strategy. in Sociobiology: Beyond

542 nature/nurture (eds. Barlow, G. W. \& Silverberg J.) 331-367 (Westview Press, 1980).

543 27. West Eberhard, M. J. Phenotypic Plasticity and the Origins of Diversity. Annu. Rev. Ecol. Syst. 20, $544 \quad 249-278(1989)$.

545 28. Moran, N. A. The evolutionary maintenance of alternative phenotypes. Am. Nat. 139, 971-989 $546 \quad$ (1992).

547 29. Walters, J. R., Doerr, P. D. \& Carter, J. H. Delayed dispersal and reproduction as a life-history 548 tactic in cooperative breeders: fitness calculations from red-cockaded woodpeckers. Am. Nat. 139, 623-643 (1992).

30. Ekman, J., Eggers, S., Griesser, M. \& Tegelström, H. Queuing for preferred territories: Delayed dispersal of Siberian jays. J. Anim. Ecol. 70, 317-324 (2001).

552 31. Bergmüller, R., Heg, D. \& Taborsky, M. Helpers in a cooperatively breeding cichlid stay and pay or disperse and breed, depending on ecological constraints. Proc. R. Soc. B Biol. Sci. 272, 325-331 (2005).

32. Kingma, S. A., Bebbington, K., Hammers, M., Richardson, D. S. \& Komdeur, J. Delayed dispersal

33. Rubenstein, D. R. Superb starlings: cooperation and conflict in an unpredictable environment. in Cooperative Breeding in Vertebrates: Studies of Ecology, Evolution, and Behavior (eds. Koenig

Walter, D. \& Dickinson, J. L.) 181-196 (Cambridge University Press, 2016).

34. Rubenstein, D. R. Temporal but Not Spatial Environmental Variation Drives Adaptive Offspring Sex Allocation in a Plural Cooperative Breeder. Am. Nat. 170, 155 (2007).

35. Pollack, L. \& Rubenstein, D. R. The fitness consequences of kin-biased dispersal in a 
cooperatively breeding bird. Biol. Lett. 11, 20150336 (2015).

565 36. Rubenstein, D. R. \& Lovette, I. J. Temporal Environmental Variability Drives the Evolution of Cooperative Breeding in Birds. Curr. Biol. 17, 1414-1419 (2007).

567 37. Rubenstein, D. R. Territory quality drives intraspecific patterns of extrapair paternity. Behav. Ecol. 18, 1058-1064 (2007).

569 38. Rubenstein, D. R. Spatiotemporal environmental variation, risk aversion, and the evolution of

39. Rubenstein, D. R., Skolnik, H., Berrio, A. \& Frances, A. Sex-specific fitness effects of unpredictable early life conditions are associated with DNA methylation in the avian

40. Rubenstein, D. R. Stress hormones and sociality: integrating social and environmental stressors. Proc. R. Soc. B Biol. Sci. 274, 967-975 (2007).

41. Guindre-Parker, S. \& Rubenstein, D. R. Multiple benefits of alloparental care in a fluctuating environment. R. Soc. Open Sci. 5, 172406 (2018).

42. Guindre-Parker, S. \& Rubenstein, D. R. Survival benefits of group living in a fluctuating environment. Am. Nat. 195, 1027-1036 (2020).

43. Suh, Y. H., Pesendorfer, M. B., Tringali, A., Bowman, R. \& Fitzpatrick, J. W. Investigating social and environmental predictors of natal dispersal in a cooperative breeding bird. Behav. Ecol. 31,

44. Meylan, S., Miles, D. B. \& Clobert, J. Hormonally mediated maternal effects, individual strategy and global change. Philos. Trans. R. Soc. B Biol. Sci. 367, 1647-1664 (2012).

45. Van Petegem, K. H. P. et al. Empirically simulated spatial sorting points at fast epigenetic changes in dispersal behaviour. Evol. Ecol. 29, 299-310 (2015). postnatal determinants of dispersal in the common lizard (Lacerta vivipara). Horm. Behav. 42, $319-326$ (2002). 
590 47. Cant, M. A., Otali, E. \& Mwanguhya, F. Eviction and dispersal in co-operatively breeding banded mongooses (Mungos mungo). J. Zool. 254, 155-162 (2001).

592 48. Nelson-Flower, M. J. \& Ridley, A. R. Nepotism and subordinate tenure in a cooperative breeder. Biol. Lett. 12, (2016).

594 49. Marshall, D. J. \& Uller, T. Why is a maternal effect adaptive? Oikos 116, 1957-1963 (2007).

595 50. Korb, J. \& Schmidinger, S. Help or disperse? Cooperation in termites influenced by food 596 conditions. Behav. Ecol. Sociobiol. 56, 89-95 (2004).

597 51. Nichols, H. J., Bell, M. B. V., Hodge, S. J. \& Cant, M. A. Resource limitation moderates the 598 adaptive suppression of subordinate breeding in a cooperatively breeding mongoose. Behav. Ecol. 23, 635-642 (2012).

600 52. Kennedy, P., Higginson, A. D., Radford, A. N. \& Sumner, S. Altruism in a volatile world. Nature 555, 359-362 (2018).

53. Ligon, J. D., Stacey, P. B. \& Ligon, J. D. The Benefits-of-Philopatry Hypothesis for the Evolution of Cooperative Breeding: Variation in Territory Quality and Group Size Effects. Am. Nat. 137, 831-846 (1991).

54. Ligon, J. D. \& Ligon, S. H. The cooperative breeding behavior of the green woodhoopoe. Sci. Am.

607 55. Sparkman, A. M., Adams, J. R., Steury, T. D., Waits, L. P. \& Murray, D. L. Direct fitness benefits of delayed dispersal in the cooperatively breeding red wolf (Canis rufus). Behav. Ecol. 22, 199-

610 56. MacColl, A. D. C. \& Hatchwell, B. J. Determinants of lifetime fitness in a cooperative breeder, the 611 long-tailed tit Aegithalos caudatus. J. Anim. Ecol. 73, 1137-1148 (2004).

612 57. Antunes, D. F. \& Taborsky, B. Early social and ecological experience triggers divergent 613 reproductive investment strategies in a cooperative breeder. Sci. Rep. 10, 1-8 (2020).

614 58. Green, J. P. \& Hatchwell, B. J. Inclusive fitness consequences of dispersal decisions in a 615 cooperatively breeding bird, the long-tailed tit (Aegithalos caudatus). Proc. Natl. Acad. Sci. 
617 59. Clutton-Brock, T. H. et al. Evolution and development of sex differences in cooperative behavior 618 in meerkats. Science (80-. ). 297, 253-256 (2002).

619 60. Stearns, S. C. Trade-Offs in Life-History Evolution. Funct. Ecol. 3, 259-268 (1989).

620 61. Wright, J., McDonald, P. G., Te Marvelde, L., Kazem, A. J. N. \& Bishop, C. M. Helping effort increases with relatedness in bell miners, but 'unrelated' helpers of both sexes still provide

62. Emlen, S. T. \& Wrege, P. H. The role of kinship in helping decisions among white-fronted beeeaters. Behav. Ecol. Sociobiol. 23, 305-315 (1988).

63. Komdeur, J. The effect of kinship on helping in the cooperative breeding Seychelles warbler (Acrocephalus sechellensis). Proc. R. Soc. B Biol. Sci. 256, 47-52 (1994).

64. Creel, S. R. \& Rabenold, K. N. Inclusive fitness and reproductive strategies in dwarf mongooses. Behav. Ecol. 5, 339-348 (1994).

65. Lampert, K. P. \& Linsenmair, K. E. Alternative life cycle strategies in the West African reed frog Hyperolius nitidulus: The answer to an unpredictable environment? Oecologia 130, 364-372 (2002).

66. Beldade, P., Mateus, A. R. A. \& Keller, R. A. Evolution and molecular mechanisms of adaptive

634 67. Saastamoinen, M. et al. Genetics of dispersal. Biol. Rev. 93, 574-599 (2018).

635 68. Gibbs, H. L. \& Grant, P. R. Oscillating selection on Darwin's finches. Nature 327, 511-513 636 (1987).

637 69. Holekamp, K. E. \& Smale, L. Dispersal status influences hormones and behavior in the male 638 spotted hyena. Horm. Behav. 33, 205-216 (1998).

639 70. Clarke, M. F. Co-operative breeding by the Australian Bell Miner Manorina melanophrys Latham: 640 A test of kin selection theory. Behav. Ecol. Sociobiol. 14, 137-146 (1984).

641 71. Russell, A. F., Portelli, D. J., Russell, D. J. F. \& Barclay, H. Breeding ecology of the Chestnut- 
crowned Babbler: A cooperative breeder in the desert. Emu 110, 324-331 (2010).

643 72. Brown, J. L., Brown, E. R., Sedransk, J. \& Ritter, S. Dominance, age, and reproductive success in 644 a complex society: A long-term study of the Mexican Jay. Auk 114, 279-286 (1997).

645 73. Hegner, R. E., Emlen, S. T. \& Demong, N. J. Spatial organization of the white-fronted bee•eater. 646 264-266 (1982).

647 74. Rowley, I., Russell, E., Payne, R. B. \& Payne, L. L. Plural breeding in the Splendid Fairy-wren, 648 Malurus splendens (Aves: Maluridae), a cooperative breeder. Ethology 83, 229-247 (1989).

649 75. Curry, R. L. \& Grant, P. R. Galapagos mockingbirds: territorial cooperative breeding in a 650 climatically variable environment. in Cooperative breeding in birds (eds. Stacey, P. B. \& Koenig, W. D.) 291-331 (Cambridge University Press, 1990).

652 76. Rowley, I. Communal Activities Among White-Winged Choughs Corcorax Melanorhamphus. Ibis 653 (Lond. 1859). 120, 178-197 (1978).

654 77. Veltman, C. J. Flock, pair and group living lifestyles without cooperative breeding by Australian Magpies Gymnorhina tibicen. Ibis (Lond. 1859). 131, 601-608 (2008).

656 78. Rubenstein, D. R. The evolution of the social and mating systems of the plural cooperatively 657 breeding superb starling, Lamprotornis Superbus. (Cornell University, 2006).

658 79. Rubenstein, D. R. Isolation and characterization of polymorphic microsatellite loci in the plural cooperatively breeding superb starling, Lamprotornis superbus. Mol. Ecol. Notes 5, 739-744 (2005).

80. Kalinowski, S. T., Taper, M. L. \& Marshall, T. C. Revising how the computer program CERVUS

664 81. Weinman, L. R., Solomon, J. W. \& Rubenstein, D. R. A comparison of single nucleotide polymorphism and microsatellite markers for analysis of parentage and kinship in a cooperatively

667 82. Apakupakul, K. \& Rubenstein, D. R. Bateman's principle is reversed in a cooperatively breeding 
bird. Biol. Lett. 11, (2015).

669 83. Rubenstein, D. R. Female extrapair mate choice in a cooperative breeder: trading sex for help and increasing offspring heterozygosity. Proc. R. Soc. B Biol. Sci. 274, 1895-1903 (2007).

84. Queller, D. C. \& Goodnight, K. F. Estimating Relatedness Using Genetic Markers. Evolution (N.

673 85. Pew, J., Wang, J., Muir, P. \& Frasier, T. related: an R package for analyzing pairwise relatedness data based on codominant molecular markers. (2015).

86. Griffiths, R., Double, M. C., Orr, K. \& Dawson, R. J. G. A DNA test to sex most birds. Mol. Ecol. 7, 1071-1075 (1998).

87. Caylor, K. K., Gitonga, J. \& Martins, D. J. Mpala Research Centre Meteorological and Hydrological Dataset [Datafile]. (2017).

88. Schielzeth, H. Simple means to improve the interpretability of regression coefficients. Methods Ecol. Evol. 1, 103-113 (2010).

89. Engqvist, L. The mistreatment of covariate interaction terms in linear model analyses of behavioural and evolutionary ecology studies. Anim. Behav. 70, 967-971 (2005).

90. Pasch, B., Bolker, B. M. \& Phelps, S. M. Interspecific dominance via vocal interactions mediates altitudinal zonation in neotropical singing mice. Am. Nat. 182, (2013).

687 92. Therneau, T. A Package for Survival Analysis in R. (2020).

688 93. R Core Team. R: A language and environment for statistical computing. (2019).

689 94. Fox, J. \& Monette, G. Generalized collinearity diagnostics. J. Am. Stat. Assoc. 87, 178-183 (1992).

691 95. Bourne, A. R., Cunningham, S. J., Spottiswoode, C. N. \& Ridley, A. R. High temperatures drive offspring mortality in a cooperatively breeding bird. Proc. R. Soc. B Biol. Sci. 287, 20201140 (2020). 
bioRxiv preprint doi: https://doi.org/10.1101/2021.02.10.430612; this version posted May 12, 2021. The copyright holder for this preprint (which

was not certified by peer review) is the author/funder, who has granted bioRxiv a license to display the preprint in perpetuity. It is made available under aCC-BY-NC-ND 4.0 International license.

694 96. Ridley, A. R., Wiley, E. M., Bourne, A. R., Cunningham, S. J. \& Nelson-Flower, M. J.

695 Understanding the potential impact of climate change on the behavior and demography of social

696 species: The pied babbler (Turdoides bicolor) as a case study. in Advances in the Study of

697 Behavior 1-42 (Elsevier Inc., 2021). doi:10.1016/bs.asb.2021.03.005.

698

699 


\section{Figures}

701

702

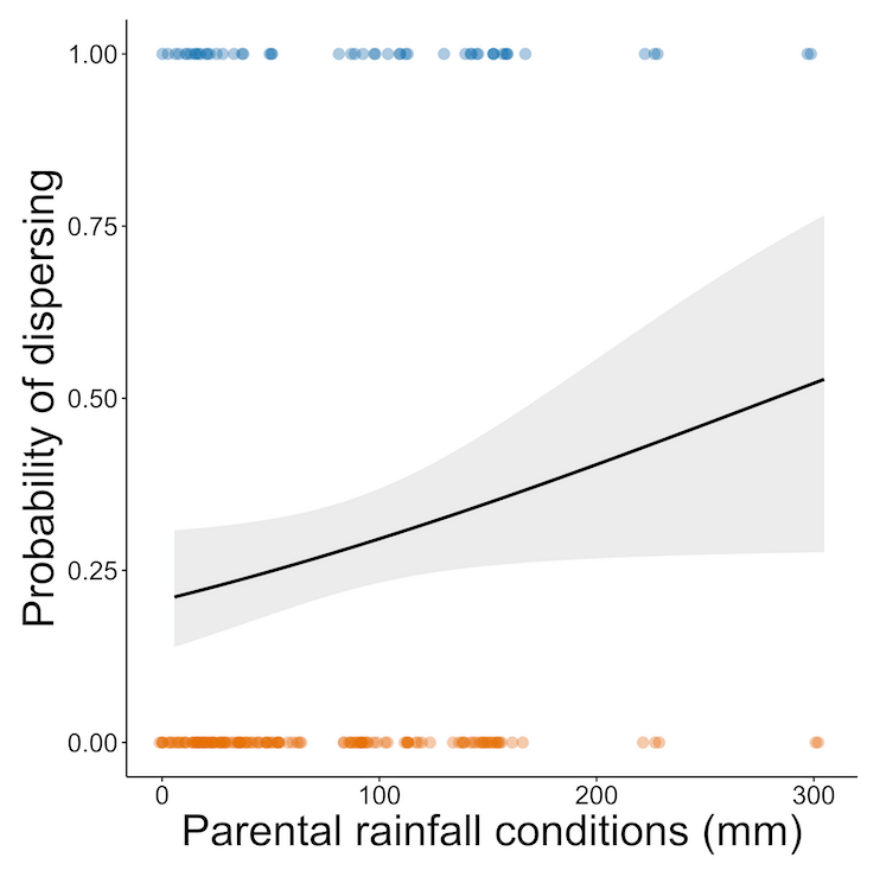

704

Figure 1. Effect of prenatal rainfall on the probability of male superb starlings dispersing from

their natal groups. Males were more likely to disperse when born following periods of higher prenatal

707 rainfall $(\mathrm{N}=185, \mathrm{P}=0.04)$. Model estimate (solid line) is bounded by the $95 \%$ confidence interval

708 (shaded areas). Circles indicate raw data (blue $=$ dispersed, orange $=$ remained). 
A

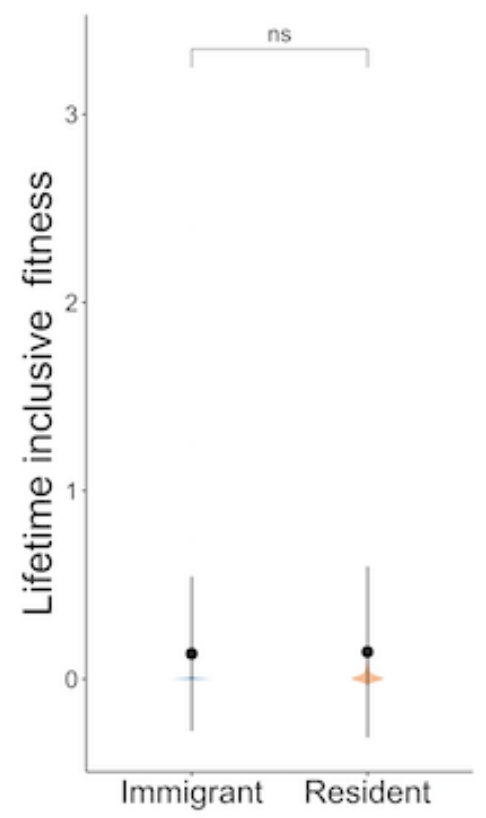

B

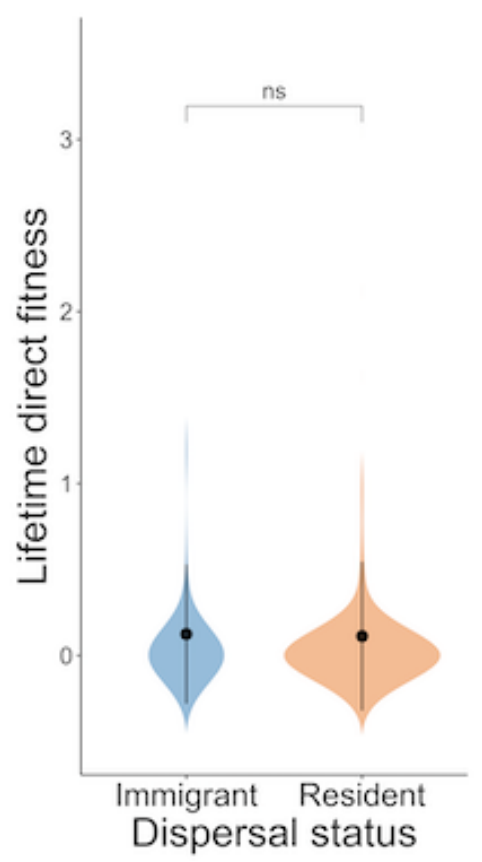

c

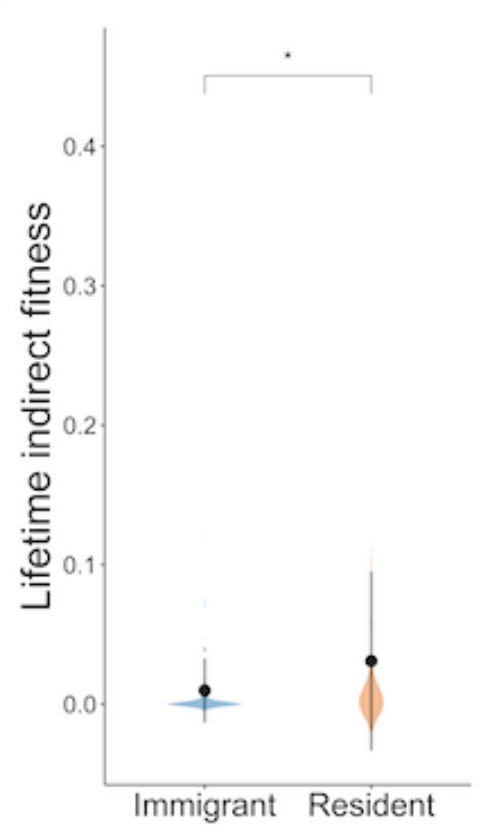

712 Figure 2. Mean lifetime fitness of immigrant and resident male superb starlings. Immigrant and

713 resident males $\left(\mathrm{N}_{\mathrm{Imm}}=59, \mathrm{~N}_{\text {Res }}=99\right)$ have equal lifetime $(\mathrm{A})$ inclusive $(\mathrm{P}=0.22)$ and $(\mathrm{B})$ direct fitness (P

$714=0.59)$, though residents have higher $(\mathrm{C})$ indirect fitness $(\mathrm{P}=0.02)$. Black dots represent means and error

715 bars denote standard deviation. Shaded areas are kernel probability densities illustrating the distribution of

716 the data. Asterisks indicate significance (ns: $\mathrm{P}>0.05 ; *$ : $\mathrm{P}<0.05)$. 
A

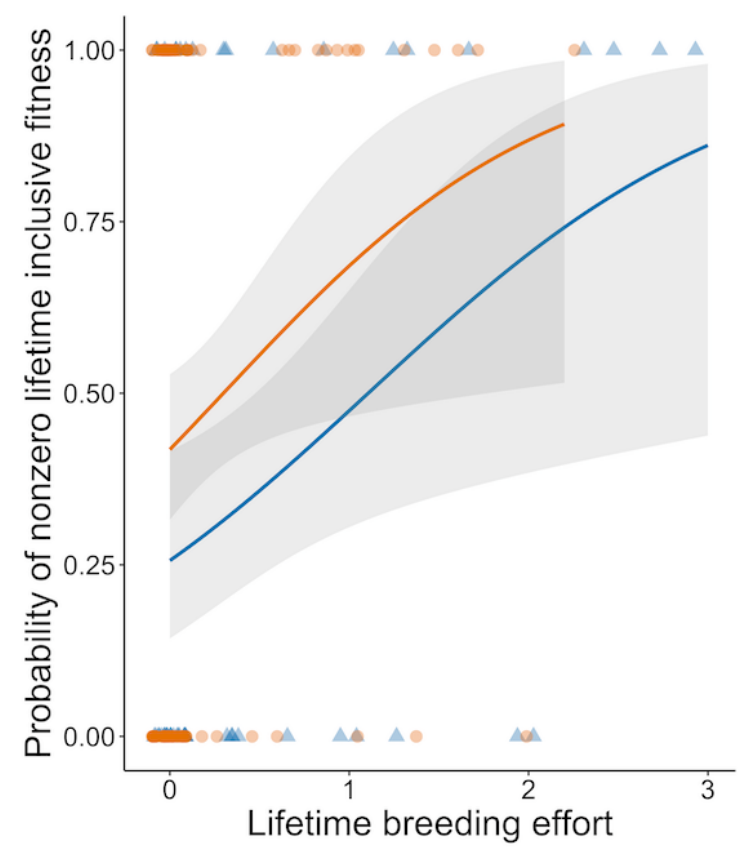

B

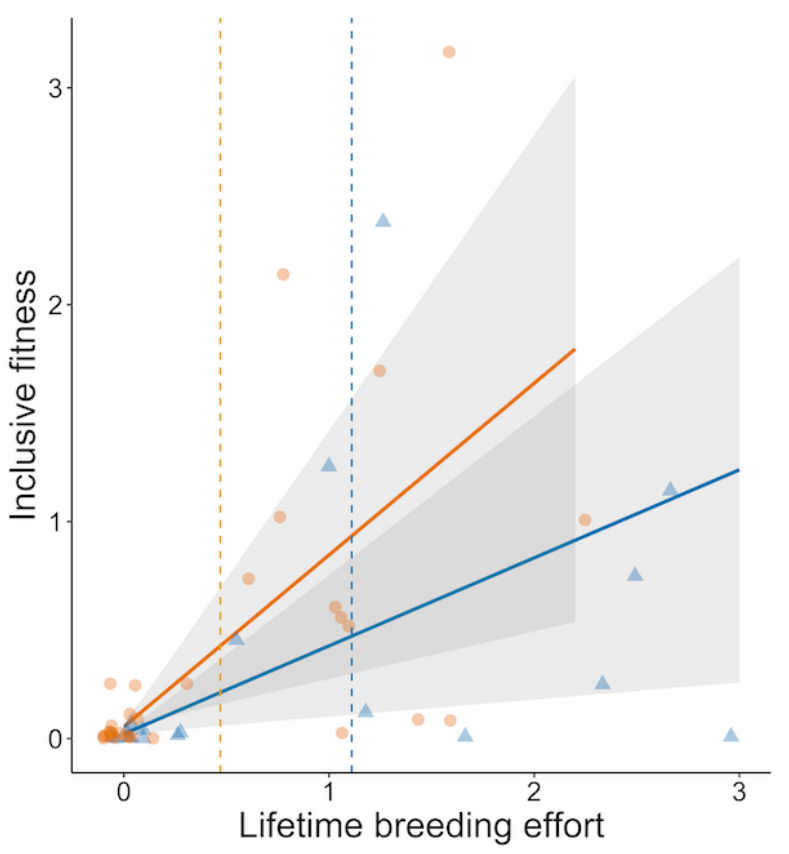

718 Figure 3. Effect of reproductive tradeoffs on lifetime inclusive fitness of male superb starlings. The

719 effect of lifetime breeding effort and dispersal status (immigrants = blue, triangles; residents = orange,

720 circles) on (A) the probability of accruing any nonzero lifetime inclusive fitness $(\mathrm{N}=152)$, and (B) the

721 value of nonzero lifetime inclusive fitness $(\mathrm{N}=67)$. For visualization purposes, we excluded one

722 individual with lifetime breeding effort greater than three standard deviations above the mean; this

723 individual was included in the statistical analysis, though excluding it did not alter the results. Lifetime

724 breeding effort (i.e., the number of breeding attempts as a proportion of an individual's adult lifespan) (P

$725=0.001)$ and dispersal status $(\mathrm{P}=0.04)$ affected a male's likelihood of accruing some nonzero inclusive

726 fitness during his lifetime. Among males with some lifetime inclusive fitness, residents accrued higher

727 inclusive fitness than immigrants for the same amount of lifetime breeding effort $(\mathrm{P}=0.04)$. Model

728 estimates (solid lines) are bound by $95 \%$ confidence intervals (shaded areas). Points indicate raw data.

729 Dashed vertical lines indicate mean lifetime breeding effort. 


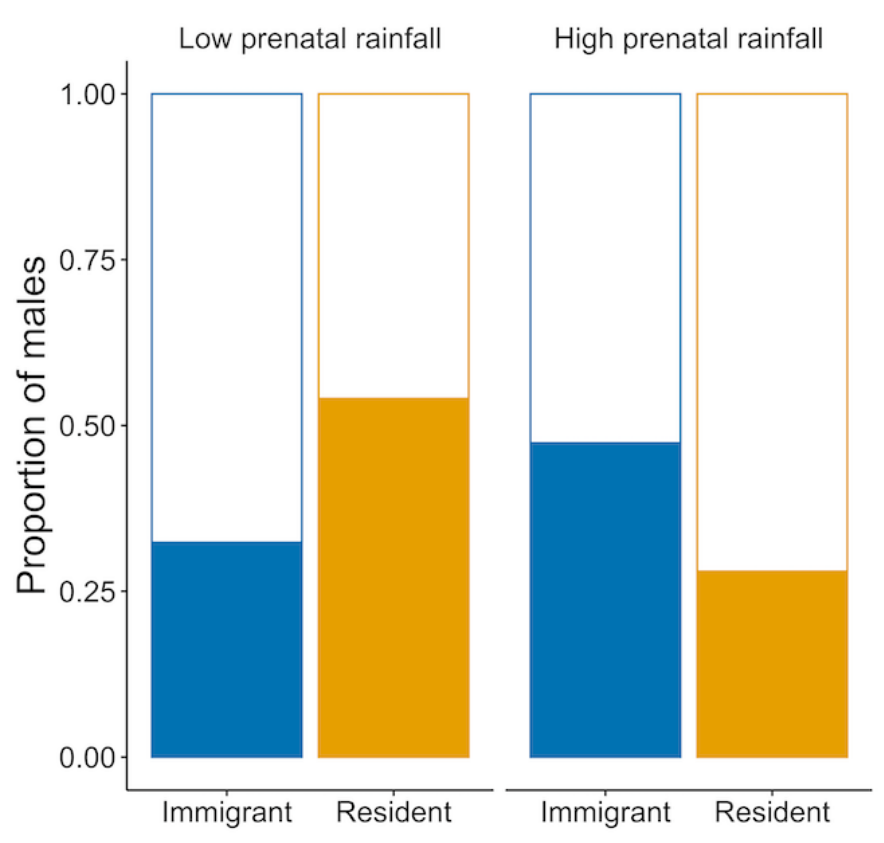

733 Figure 4. Fitness consequences of male superb starlings adopting the tactic not predicted by the

734 prevailing prenatal environmental conditions. The effect of prenatal rainfall and dispersal status

735 (immigrants $=$ blue, residents $=$ orange) on the probability of accruing any nonzero lifetime inclusive

736 fitness (fill = nonzero fitness, no fill = zero fitness $)(\mathrm{N}=152)$. Immigrants were more likely to accrue

737 nonzero lifetime inclusive fitness when born following periods of high prenatal rainfall, whereas residents

738 were more likely to accrue nonzero lifetime inclusive fitness when born following periods of low prenatal

739 rainfall $(\mathrm{P}=0.02)$. 
740 Table 1. Factors affecting dispersal decisions of natal male superb starlings. Results of a generalized

741 linear mixed model with a binomial response (dispersed vs. remained) for natal males $(\mathrm{N}=185)$. Since

742 sex ratio and group size are highly correlated within a year, we only included the former in the final

743 model. Breeding season was included as a random effect. Random effects of social group, father ID,

744 mother ID, and season (short vs. long rains) had variance components equal to zero, and were thus

745 excluded from the final model to facilitate the computation of $95 \%$ confidence intervals.

\begin{tabular}{lcccccc}
\hline Effect & Estimate & Std. Error & $\mathrm{Z}$ value & \multicolumn{2}{c}{$95 \%$ CI } & $\mathrm{p}$-value \\
\hline Intercept & -0.97 & 0.18 & -5.45 & -1.36 & -0.60 & $<0.001$ \\
Prenatal rainfall & 0.36 & 0.18 & 2.03 & 0.02 & 0.74 & 0.04 \\
Prenatal sex ratio & -0.13 & 0.20 & -0.68 & -0.54 & 0.24 & 0.50 \\
Prenatal group size & 0.05 & 0.19 & 0.27 & -0.34 & 0.44 & 0.78 \\
Juvenile rainfall & -0.12 & 0.17 & -0.69 & -0.48 & 0.24 & 0.49 \\
\hline
\end{tabular}




\section{Table 2. Effects of lifetime breeding effort and dispersal status on lifetime inclusive fitness of male}

748 superb starlings. Results of generalized linear mixed models with a (A) binomial (zero vs. nonzero) $(\mathrm{N}=$

749 152) and (B) continuous, positive $(\mathrm{N}=67)$ response variable for lifetime inclusive fitness of males. Social

750 group was included as a random effect in the first model, but since it explained none of the variance and

751 hindered the calculation of $95 \%$ confidence intervals for the fixed effects, we removed it from the second

752 model.

(A) Response variable: binomial (zero/nonzero) lifetime inclusive fitness

\begin{tabular}{lcccccc}
\hline Effect & Estimate & Std. Error & Z value & \multicolumn{2}{c}{$95 \%$ CI } & p-value \\
\hline Intercept & -1.10 & 0.35 & -3.14 & -1.86 & -0.44 & 0.002 \\
Lifetime breeding effort & 1.03 & 0.31 & 3.28 & 0.46 & 1.72 & 0.001 \\
Dispersal status & 0.78 & 0.39 & 2.02 & 0.01 & 1.56 & 0.04 \\
\hline
\end{tabular}

(B) Response variable: continuous, positive lifetime inclusive fitness

\begin{tabular}{lcccccc}
\hline Effect & Estimate & Std. Error & t value & \multicolumn{2}{c}{$95 \%$ CI } & \multicolumn{2}{c}{-value } \\
\hline Intercept & 0.02 & 0.01 & 2.04 & 0.01 & 0.06 & 0.04 \\
Lifetime breeding effort & 0.55 & 0.15 & 3.73 & 0.33 & 0.95 & $<0.001$ \\
Dispersal status & 0.04 & 0.02 & 2.27 & -0.00 & 0.08 & 0.03
\end{tabular}


bioRxiv preprint doi: https://doi.org/10.1101/2021.02.10.430612; this version posted May 12, 2021. The copyright holder for this preprint (which

was not certified by peer review) is the author/funder, who has granted bioRxiv a license to display the preprint in perpetuity. It is made available under aCC-BY-NC-ND 4.0 International license.

754 Table 3. Effects of male superb starlings adopting the tactic not predicted by the prevailing

755 prenatal ecological conditions on the likelihood of gaining nonzero inclusive fitness during their

756 lifetimes. Results of a generalized linear mixed model with a binomial response (zero vs. nonzero lifetime

757 inclusive fitness) variable for males $(\mathrm{N}=152)$. Social group was included as a random effect.

758

\begin{tabular}{lcccccc}
\hline Effect & Estimate & Std. Error & Z value & \multicolumn{2}{c}{$95 \%$ CI } & \multicolumn{1}{c}{ p-value } \\
\hline Intercept & -0.10 & 0.46 & -0.23 & -1.03 & 0.80 & 0.82 \\
Categorical prenatal rainfall & -0.63 & 0.59 & -1.08 & -0.80 & 0.52 & 0.28 \\
Dispersal status & -0.84 & 0.64 & -1.31 & -2.13 & 0.40 & 0.19 \\
Categorical prenatal rainfall x & 1.74 & 0.77 & 2.25 & 0.24 & 3.29 & 0.02 \\
Dispersal status & & & & & &
\end{tabular}

